\title{
LOCALIZAÇÃO DE SCHISTOSOMA MANSONI NO PLEXO PORTA DE MUS MUSCULUS EXPERIMENTALMENTE INFECTADOS POR UM SÓ SEXO DO TREMATÓDEO *
}

\author{
Eliana Maria Zanotti **
}

Luiz Augusto Magalhães **

Aquiles Eugenico Piedrabuena**

\begin{abstract}
ZANOTTI, E. M. et al. Localizacão de Schistosoma mansoni no plexo porta de Mus muscnlus experimentalmente infectados por um só sexo do trematódeo. Rev. Saúde públ., S. Paulo, 16:220-32, 1982.

RESUMO: Foi estudado o hábito migratório de Schistosoma mansoni em infecçóes bissexuais e nas produzidas por um só sexo do trematódeo, tendo sido evidenciada a influência do sexo no deslocamento dos esquistossomos. Nas infecçóes bissexuais parece que o deslocamento dos vermes para os vasos mesentéricos visa o acasalamento e a oviposição.
\end{abstract}

UNITERMOS: Schistosoma mansoni, migração. Esquistossomose mansônica. Mus musculus.

\section{INTRODUÇAO}

Standen 1" (1953), estudando o hábito do início da migração é determinada pelo migratório dos esquistossomos, verificou grau de maturidade das fêmeas.

que o impulso migratório do verme macho de Schistosoma mansoni Sambon ${ }^{9}, 1907$ é grandemente estimulado pela presença da fêmea. O mesmo autor observou também que esquistossomos fêmeos, em infecções unissexuais, desenvolviam-se rapidamente, alcançando a maturidade quando colocados posteriormente em contacto com machos, através de uma segunda infecção. Concluiu ainda, em seus estudos sobre a influência do sexo na migração dos vermes do fígado para os vasos mesentéricos, que a época

Considerando que as infecções unissexuais na natureza podem ocorrer com grande freqüência, o que foj mostrado por $\mathrm{Pa}$ raense e Santos ${ }^{7}$ (1949) e Paraense ${ }^{8}$ (1949), utilizando moluscos colhidos no campo, e que a associação entre vermes machos e fêmeos é fator importante na migração de $S$. mansoni no hospedeiro definitivo, resolveu-se desenvolver a presente pesquisa visando verificar $a$ influência do acasalamento e da presença de um só sexo na distribuição de $S$. mansoni no plexo porta.

* Trabalho realizado com o auxílio do Conselho Nacional de Desenvolvimento Científico e Tecnológico - Processo n̊ 2.222-8-077/78 e Fundação de Amparo à Pesquisa do Estado de São Paulo - Processo ne 04-77/1416.

** Do Departamento de Parasitologia do Instituto de Biologia da Universidade Estadual de Campinas - Barão Geraldo - Calxa Postal 6109 - 13100 - Campinas, SP - Brasil. 
ZANOTTI, E.M. et al. Localização de Schistosoma mansoni no plexo porta de Mus musculus experimentalmente infectados por um só sexo do trematódeo. Rev. Saúde públ., S. Paulo, 16: 220-32, 1982.

\section{MATERIAL E METODOS}

Foram infectados com miracidios da linhagem $\mathrm{BH}$ exemplares de Biomphalaria glabrata descententes de ma população de Belo Horizonte, MG e criados em laboratório.

Para obter-se infecção unissexual, cada exemplar de molusco foi exposto a um único miracídio e, para infecção bissexual, cada caramujo era exposto a 10 miracídios.

Utilizando as cercárias eliminadas por esses moluscos, foram infectados pela cauda (Magalhães ${ }^{6}$, 1969) camundongos albinos com 30 dias de idade, pesando de 14 a $16 \mathrm{~g}$. Cada roedor foi exposto a 100 cercárias.

Foram constituídos 3 grupos de roedores: infectados unissexualmente for fêmeas, infectados unissexualmente por machos e infectados bissexualmente.

Subgrupos foram sacrificados semanalmente da primeira a oitava semana após a exposição às cercárias.

Para se verificar o tipo de infecção unissexual nos camundongos pertencentes ao grupo cujos componentes foram sacrificados ná primeira semana, quando não era possivel, durante a necrópsia, a obtenção de vermes já desenvolvidos, observou-se o desenvolvimento das cercárias provenientes do mesmo molusco em outro camundongo sacrificado na oitava semana.

Por ocasião da necrópsia foi registrado o número de vermes e sua localização no fígado, na veia porta e nos vasos mesentéricos (Yolles e col. ${ }^{11}$, 1947).

Foi utilizado o teste não paramétrico de Friedman para o estudo estatístico dos dados recolhidos.

\section{RESULTADOS}

A partir da segunda semana após a exposição às cercárias, constatou-se a presença de esquistossomos nos vasos do plexo porta em roedores portadores de infecção bissexual e unissexual por machos. Nos camundongos com infecção unissexual por fêmeas os esquistossomos apresentaram-se somente a partir da terceira semana.

Em razão do assincronismo do desenvolvimento, os esquistossomos foram recolhidos em diversos estádios, verificando-se até na oitava semana a presença de esquistossômulos.

Localização dos esquistossomos na infeç̧ão unissexual por fêmeas

Nas infecções unissexuais por fêmeas, os vermes mostraram-se com tamanho inferior ao normal e com o aparelho reprodutor pouco desenvolvido.

Neste tipo de infecção os esquistossomos foram encontrados principalmente no fígado e veia porta. Nos vasos mesentéricos o número de esquistossomos foi pequeno.

Os dados obtidos e o resultado da análise estatística estão contidos nas Tabelas 1,2 e 3. Para a confecção do gráfico (Fig. 1) foi aplicada uma equação algébrica de quarto grau, utilizando as teorias dos quadrados mínimos.

O número de vermes localizados no fígado e nos vasos mesentéricos, nos animais sacrificados nas terceira, quarta e quinta semanas, apresentou diferença altamente significativa, como também foi significativa a diferença entre o número de esquistossomos localizados na veia porta e nos vasos mesentéricos.

Nas sexta, sétima e oitava semanas, os vermes estavam localizados, principalmente, no fígado e na veia porta. Nos vasos mesentéricos poucos vermes foram colhidos.

Localização dos esquistossomos nas infecções unissexuais por machos

Nas Tabelas 4, 5 e 6 estão presentes os dados referentes ao número de vermes e sua localização, nos camundongos infectados por machos. 
ZANOTTI, E.M. et al. Localização de Schistosoma mansoni no plexo porta de Mus musculus experimentalmente infectados por um só sexo do trematódeo. Rev. Saúde públ., S. Paulo, 16: 220-32, 1982.

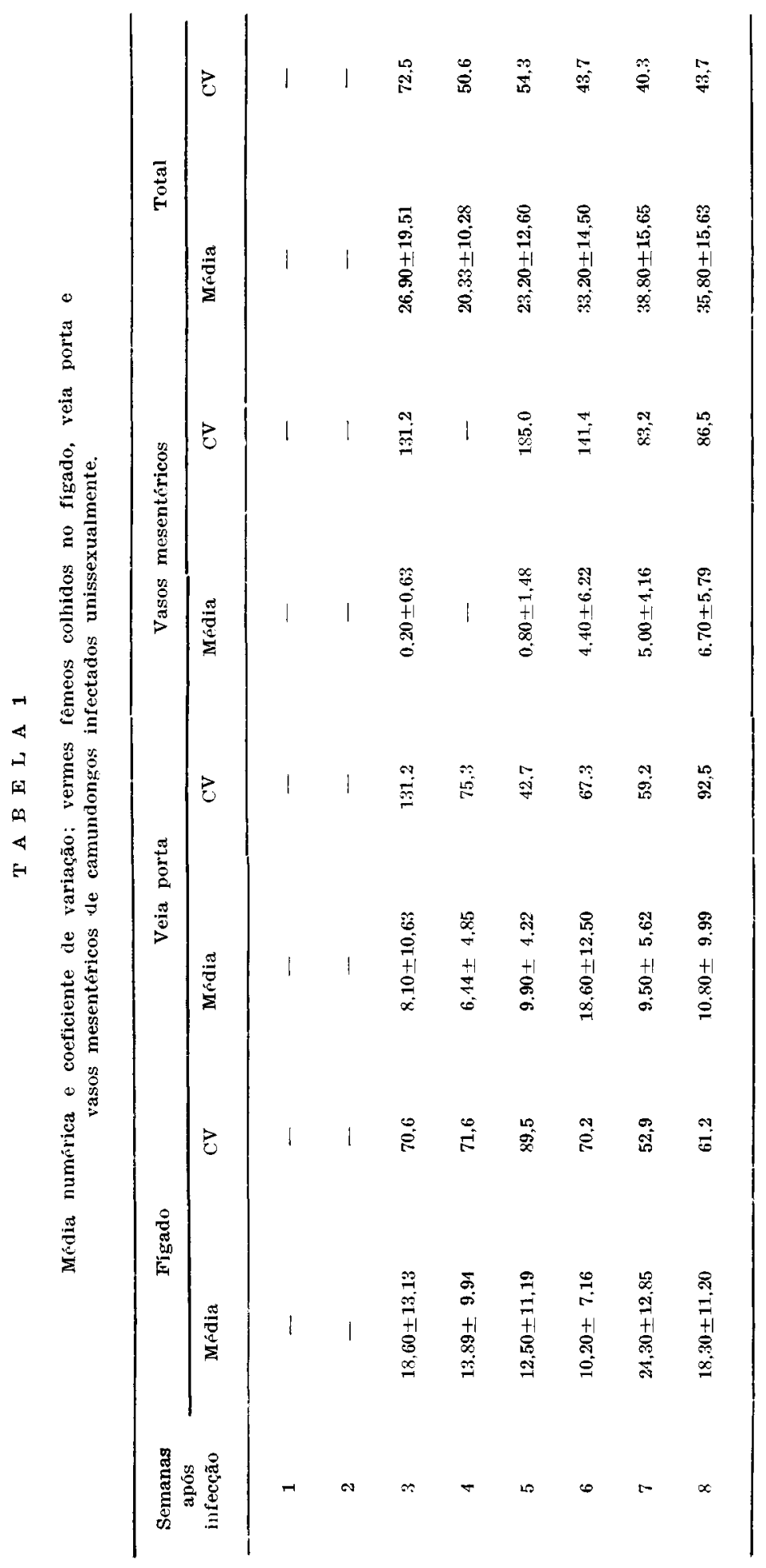


ZANOTTI, E.M. et al. Localização de Schistosoma mansoni no plexo porta de Mus musculus experimentalmente infectados por um só sexo do trematódeo. Rev. Saúde públ., S. Paulo, 16: 220-32, 1982.

T A B E L A 2

Distribuição percentual de vermes fêmeos colhidos no fígado, veia porta e vasos mesentéricos de camundongos infectados unissextalmente.*

\begin{tabular}{cccc}
\hline $\begin{array}{c}\text { Semanas } \\
\text { após } \\
\text { infeç̧ão }\end{array}$ & Fígado & Veia Porta & $\begin{array}{c}\text { Vasos } \\
\text { Mesentéricos }\end{array}$ \\
\cline { 2 - 4 } & $\%$ & $\%$ & $\%$ \\
5 & 68,3 & 31,7 & 0,0 \\
6 & 53,9 & 42,7 & 3,4 \\
7 & 30.7 & 56,0 & 13,3 \\
8 & 62,6 & 24,5 & 12,9 \\
& 51,1 & 30,2 & 18,7 \\
\hline
\end{tabular}

* Valores utilizados na elaboração do gráfico (Fig. 1) e no cálc: lo das equações.

T A E E L A 3

Resultado da análise estatística da distribuição dos esquistossomos fêmeos em camundongos infectados unissexualmente.

\begin{tabular}{|c|c|c|c|c|c|c|c|}
\hline $\begin{array}{l}\text { Semanas após } \\
\text { infeç̧ão }\end{array}$ & F-VM & VP-VM & F-VP & $\chi$ & & $\mathrm{n}$ & $\mathrm{k}$ \\
\hline 4 & $* * *$ & $*$ & NS & 14,389 & $* * *$ & 9 & 3 \\
\hline 5 & $* * *$ & $* *$ & NS & 15,450 & $\because * *$ & 10 & 3 \\
\hline 6 & NS & $*$ & NS & 8,15 & * & 10 & 3 \\
\hline 7 & $* * *$ & NS & $* *$ & 15,80 & * & 10 & 3 \\
\hline 8 & * & NS & NS & 8,15 & $*$ & 10 & 3 \\
\hline
\end{tabular}

F - Fígado; VP - veia porta; VM - vasos mesentéricos.

NS - não significativo

*** significativo a nível de $0,1 \% \quad \mathrm{n}=$ número de camundongos sacrificados

*: significativo a nível de $1 \% \quad \mathrm{k}=$ número de localização dos vermes

* significativo a nível de $5 \% \quad r=$ índice do teste de Friedman 
ZANOTTI, E.M. et al. Localização de Schistosoma mansoni no plexo porta de Mus musculus experimentalmente infectados por um só sexo do trematódeo. Rev. Saúde públ., S. Paulo, 16: 220-32, 1982.

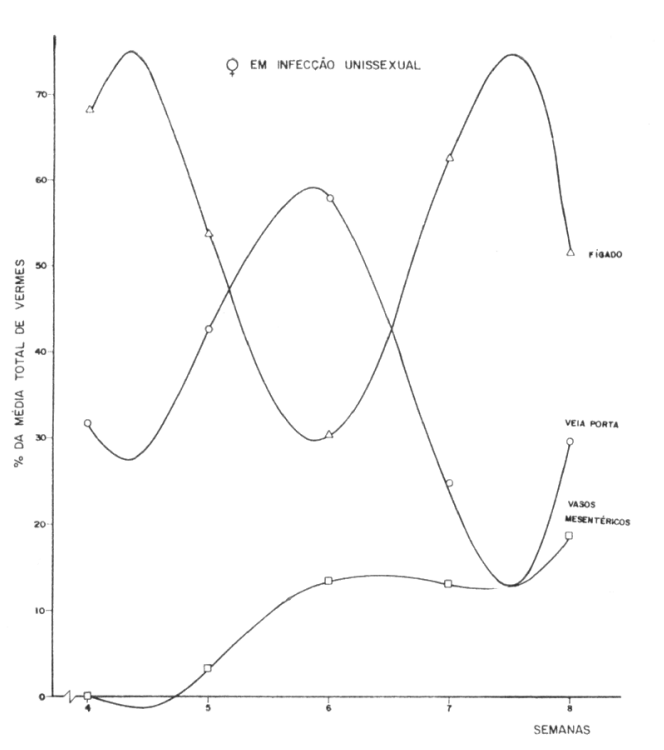

Fig. 1 - Distribuição de esquistossomos no figado, vela porta e vasos mesentéricos nas infeções unissexuais por fêmeas. Figado $\mathrm{y}=30,7+7,2333(\mathrm{x}-6)+$ $34,3167(\mathrm{x}-6) 2-2,8833(\mathrm{x}-6): 2$ $6.7667(\mathrm{x}-6) 4$.

Veia Porta $\mathrm{y}=56,0000-11,7375(\mathrm{x}-6)$ $-27,7792(x-6) 2+2,8375(x-6):$ $+5,3792(x-6) 4$.

Vasos Mesentéricos $\mathrm{y}=13,3000+$ $4,7750(\mathrm{x}-6)-6,5375(\mathrm{x}-6) 2-$ $0,0250(x-6) s+1,3875(x-6) 4$.

Nas quarta e quinta semanas diferiu, de modo significativo, o número de vermes colhidos no fígado e na veia porta, em relação aos esquistossomos colhidos nos vasos mesentéricos.

Nas três semanas subseqüentes, os esquistossomos continuaram predominando no fígado e na veia porta. Nos vasos mesentéricos foi pequeno o número de vermes observados.

O deslocamento dos machos na infecção unissexual é melhor visualizado no gráfico (Fig. 2) elaborado a partir dos valores da Tabela 5 .
Localização dos esquistossomos nas infeç̧ões bissexuais

O comportamento migratório dos esquis. tossomos nos camundongos com infecção bissexual pode ser analisado pela observação das Figs. 3, 4 e 5.

Verificamos que machos e fêmeas têm padrão de deslocamento semelhante e que se traduziram nos coeficientes das equações que interpretam as curvas, pois estas são sensivelmente iguais.

Na quarta semana, a localização dos vermes foi predominantemente intra-hepática. Nas duas semanas subseqüentes verificamos sua distribuição pelo fígado, veia porta e vasos mesentéricos, não tendo sido observadas diferenças significativas nessa distribuição.

Nas sétima e oitava semanas, encontramos ainda alguns esquistossomos no fígado; sua predominância foi, todavia, nos vasos mesentéricos e veia porta, nesta em menor número.

Os dados pertinentes aos números de vermes e sua localização na infecção bissexual, estão apresentados nas Tabelas 7 , 8,9 e 10 .

As representações gráficas das Figs. 1, $2,3,4$ e 5 não são resultados de ajustes regidos dos dados experimentais. Essas figuras são tentativas de representações gráficas dos fenômenos estudados com a finalidade de melhor expressar a movimentação dos vermes.

\section{DISCUSSÃO E CONCLUSOES}

Observando-se as Figuras 1 e 2, sobre - comportamento migratório dos vermes fêmeos e machos nas infecções unissexuais, verificamos que embora os esquistossomos predominem no fígado e veia porta, os padrões de deslocamento são diferentes. 
ZANOTTI, E.M. et al. Localização de Schistosoma mansoni no plexo porta de Mus musculus experimentalmente infectados por um só sexo do trematódeo. Rev. Saúde públ., S. Paulo, 16 : 220-32, 1982.

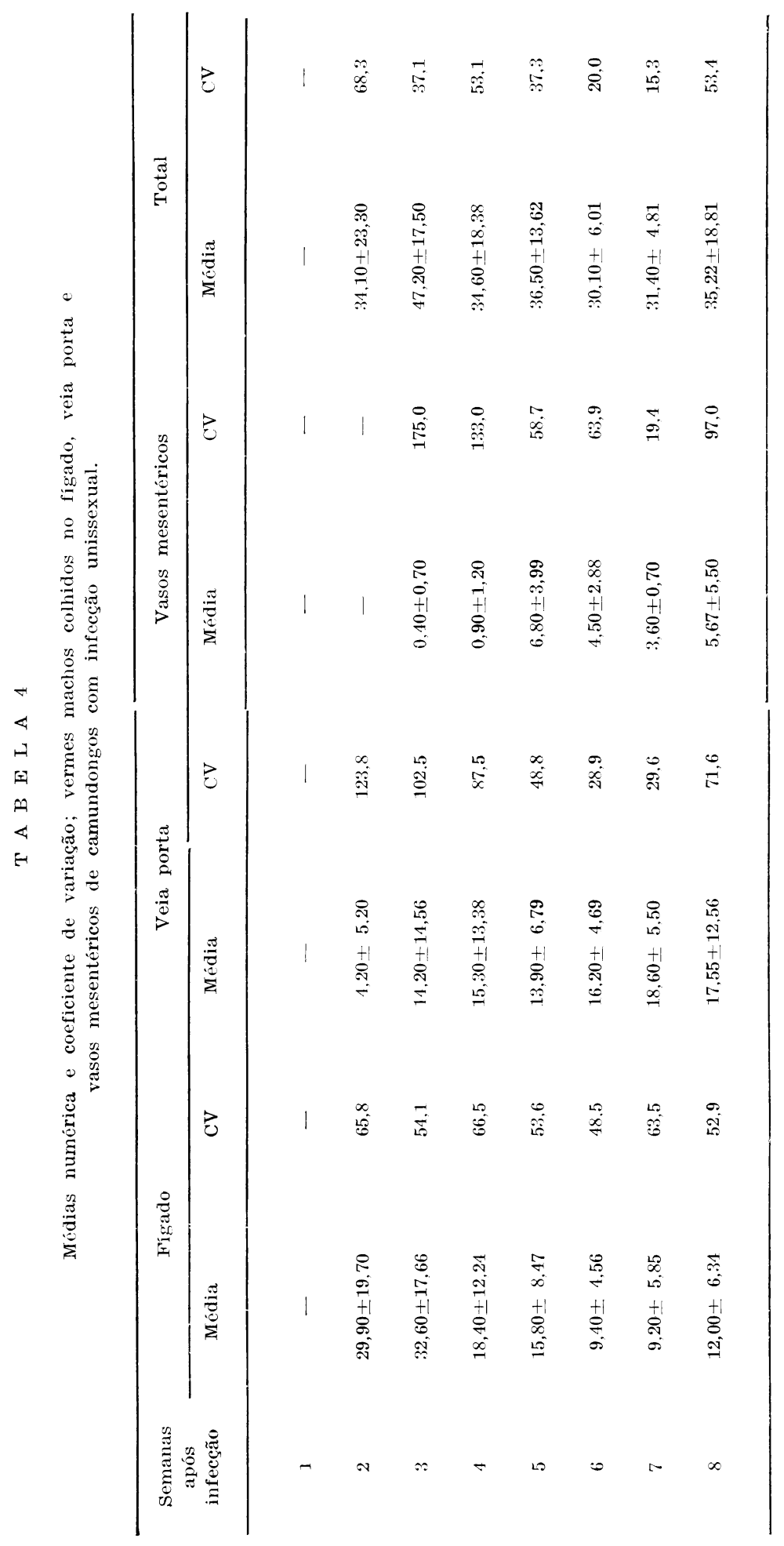


ZANOTTI, E.M. et al. Localização de Schistosoma mansoni no plexo porta de Mus musculus experimentalmente infectados por um só sexo do trematódeo. Rer. Sañde públ., S. Paulo, 16: $220-32,1982$.

T A B E L A 5

Distribuıção percentual de vermes machos colhidos no fígado, veia porta e vasos mesentéricos de camundongos infectados unissex:almente."

\begin{tabular}{cccc}
\hline $\begin{array}{c}\text { Semanas } \\
\text { após } \\
\text { infecção }\end{array}$ & Figado & Veia Porta & $\begin{array}{c}\text { Vasos } \\
\text { Mesentéricos }\end{array}$ \\
\hline 4 & $\%$ & $\%$ & $\%$ \\
5 & 53,2 & 44,2 & 2,6 \\
6 & 43.3 & 38.1 & 18.6 \\
7 & 31.2 & 53.8 & 15,0 \\
& 29.3 & 59.2 & 11,4 \\
\hline
\end{tabular}

* Vaiores utilizados na elaboração do gráfico da Fig. 2 e no cálculo das equações.

T A B E L A 6

Resultado da análise estatística da distribuição dos esquistossomos machos em camundongos infectados bissexualmente.

\begin{tabular}{l}
$\begin{array}{c}\text { Semanas } \\
\text { após } \\
\text { Infecção }\end{array}$ \\
\hline
\end{tabular}




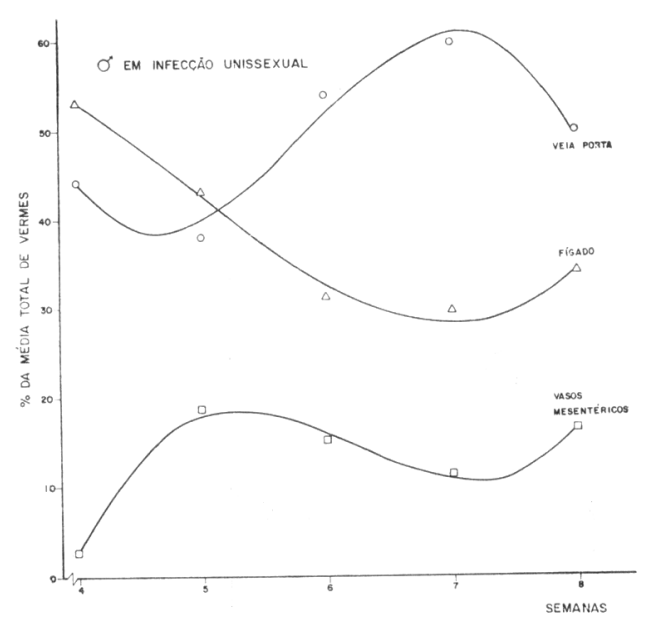

Fig. 2 - Distribuição de esquistossomos no fígado, veia porta e rasos mesentéricos nas infeçoóes unissexuais por machos. Figado $\mathrm{y}=32,5629-7.7417(\mathrm{x}-6)$ $+2.8286(\mathrm{x}-6) \mathrm{z}+0.7417(\mathrm{x}-6):$ Veia Porta $y=51.4343+13.6000$ $(x-6)-1.2071(x-6) \div-3.0500$ $(\mathrm{x}-6)$

Vasos Mesentéricos $y=15.9686-5,2250$ $(\mathrm{x}-6)-1.6143(\mathrm{x}-6) \cdot 2+2.3250$ $(\mathrm{x}-6) \cdots$

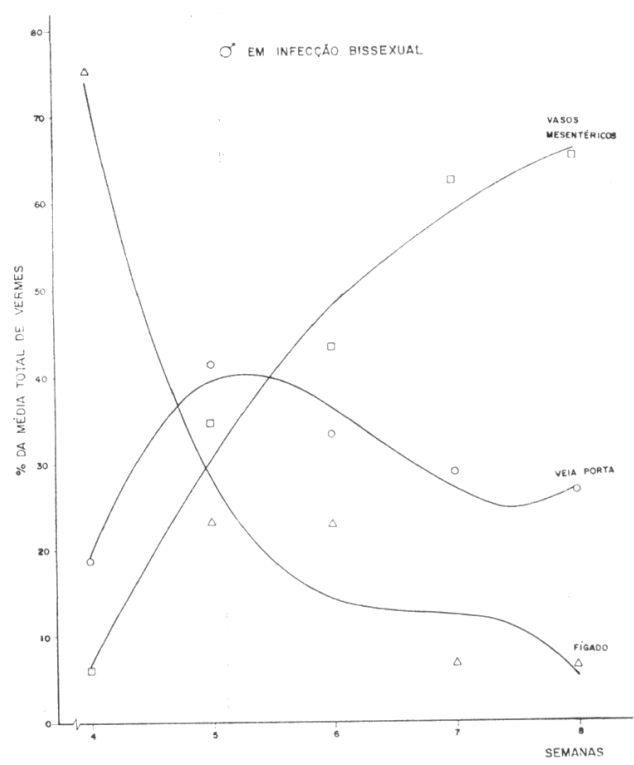

Fig. 4 - Distribuição de esquistossomos machos no figado, reia porta e vasos mesentêricos nas infecçóes bissexuais.

Figado $y=14.7371-5.1293(x-6)$ $+6.2464(x-6)=-3.0067(x-6): 3$ Veia Porta $y=36.6664-8.9175$ $(x-6)-3.2707(x-6) \div 2.7525$ $(x-6) 3$

Vasos Mesentéricos $\mathrm{y}=48.4934+$ $13.8158(\mathrm{x}-6)-2.9957(\mathrm{x}-6) \div-$ $0.2942(x-6) 3$.

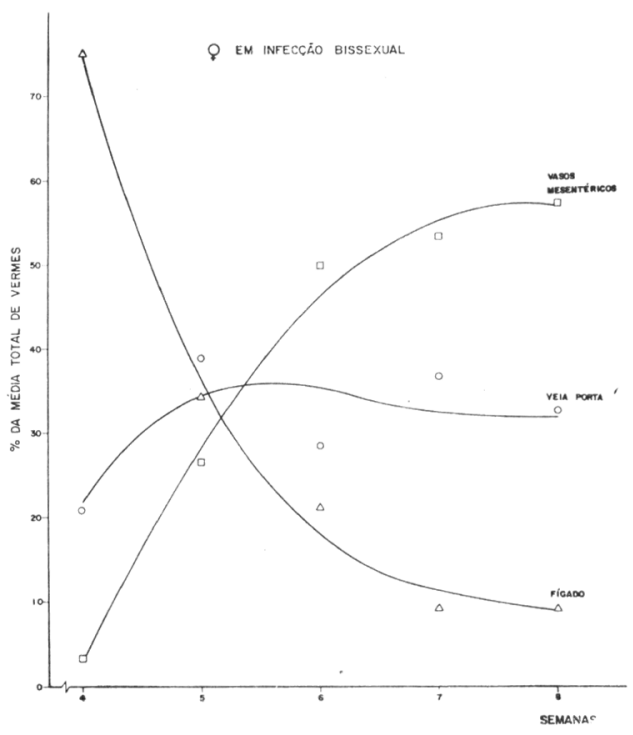

Fig. 3 - Distribuição de esquistossomos fêmeos no fígado, reia porta e rasos mesentéricos nas infeçóes bissexuais.

Figado $\mathrm{y}=18.1000-11.0725(\mathrm{x}-6)$ $+5.9500(\mathrm{x}-6) \div-1,3575(\mathrm{x}-6): 3$ Veia Porta $y=35.4494-2.2833(x-6)$ $-1.8157(x-6) 2+1,3233(x-6): 3$. Vasos Mesentéricos $y=46.4500+13.3483$ $(x-6)-4.1350(x-6):-0.0367$ $(x-6): 3$

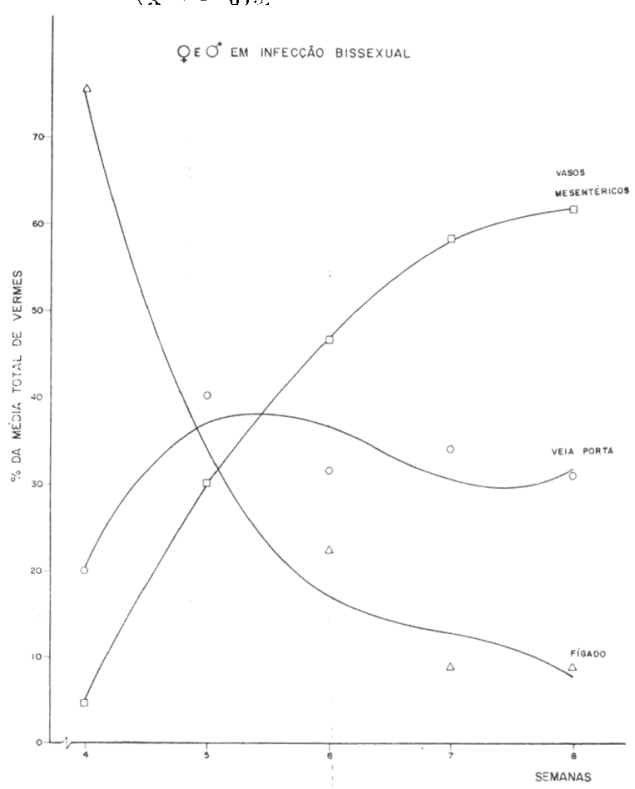

Fig. 5 -- Distribuição de esquistossomos muchos e fêmeos no fígado, veia porta e rasos mesentéricos nas infeccões bisse.uais. Figado $\mathrm{y}=16.8346-8.7033(\mathrm{x}-6)$ $+6.0307(\mathrm{x}-6) 2+2.0217(\mathrm{x}-6): 3$ Veia Porta $\mathrm{y}=36,2037-5,1675(\mathrm{x}-6)$ $-2.5279(x-6) \div+1.9525(x-6): 3$ Vasos Mesentéricos $y=46.9711$ $13.8700(x-6)-3.5043(x-6) 2$ $\perp 0.0700(x-6):$ 
ZANOTTI, E.M. et al. Localização de Schistosoma niansoni no plexo porta de Mus musculus experimentalmente infectados por um só sexo do trematódeo, Rev. Saúde públ., S. Paulo, 16: $220-32,1982$.

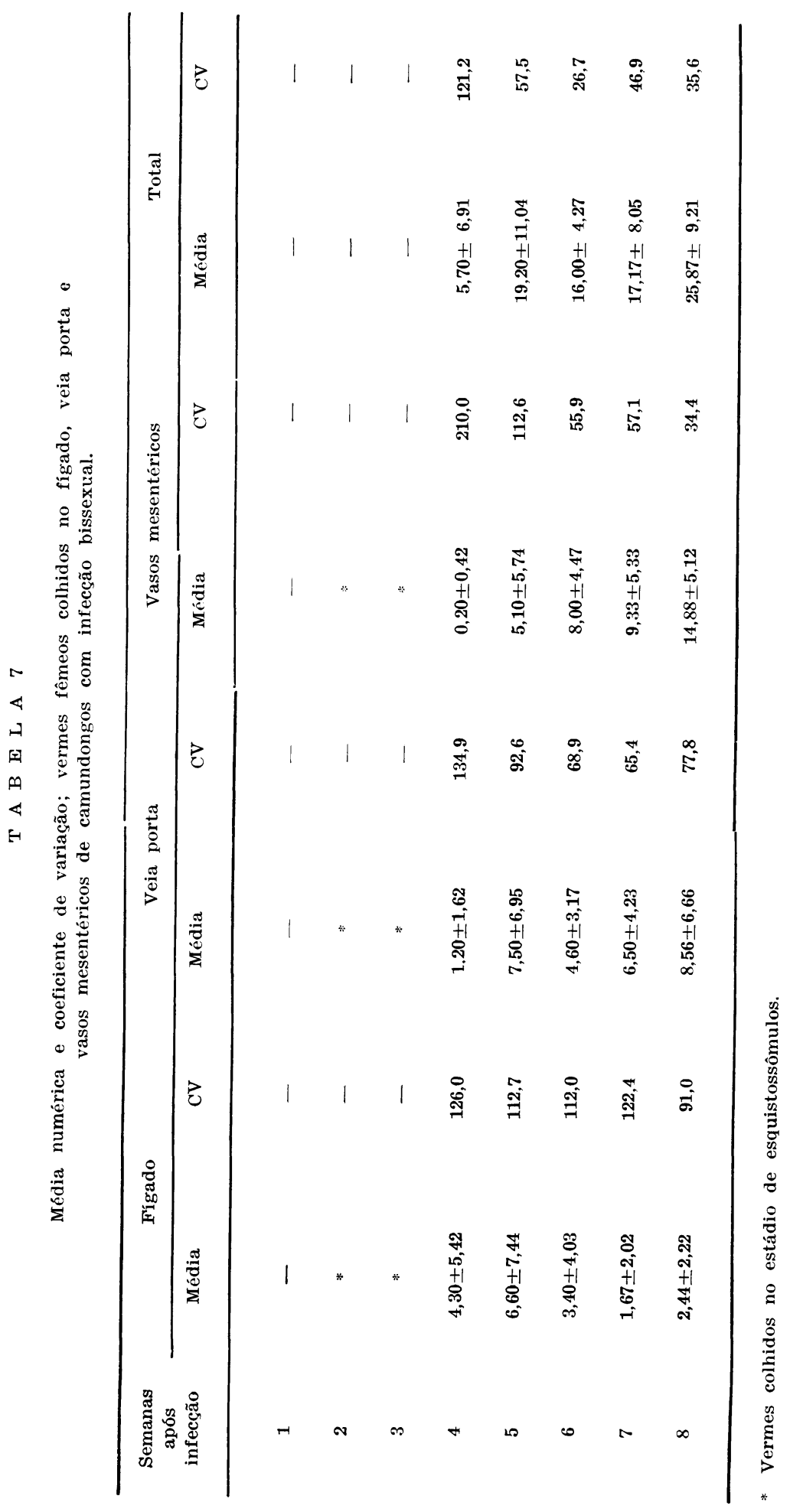


ZANOTTI, E.M. et al. Localização de Schistosoma mansoni no plexo porta de Mus musculus experimentalmente infectados por um só sexo do trematódeo. Rev. Saúde públ., $\mathbf{S}$. Paulo, 16: 220-32, 1982 .

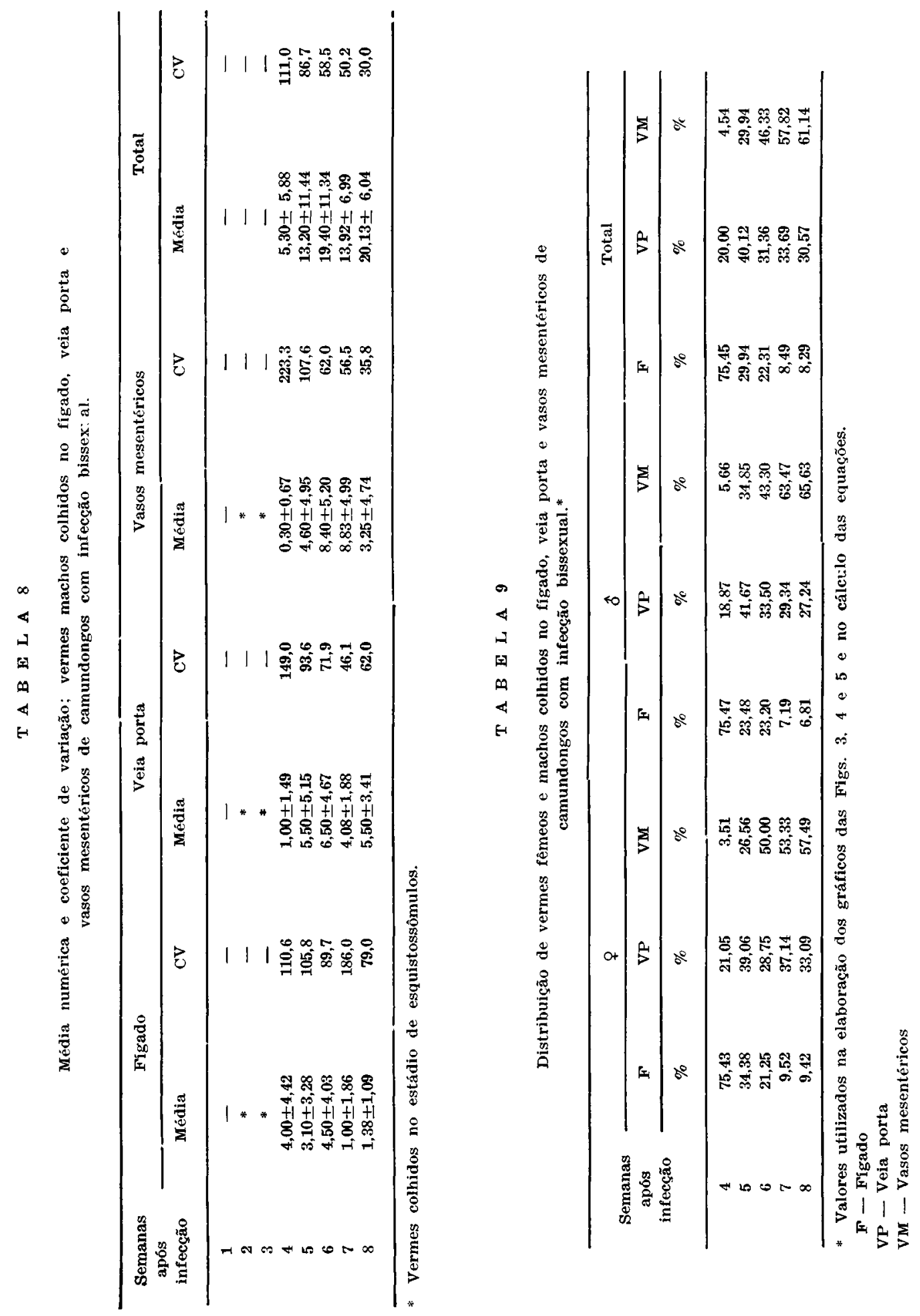


ZANOTTI, E.M. et al. Localização de Schistosoma mansoni no plexo porta de Mus musculus experimentalmente infectados por um só sexo do trematódeo. Rev. Saúde públ., S. Paulo, 16: $220-32,1982$.

\begin{tabular}{|c|c|c|c|c|c|c|c|}
\hline \multicolumn{8}{|c|}{ infectados bissexualmente. } \\
\hline $\begin{array}{c}\text { Semanas } \\
\text { após } \\
\text { infecção }\end{array}$ & & F-VM & $\mathrm{VP}-\mathrm{VM}$ & $\mathrm{F}-\mathrm{VP}$ & $\chi_{1}^{2}$ & $\mathrm{n}$ & $\mathrm{k}$ \\
\hline 4 & & $* * *$ & NS & $*$ & $20,00 * * *$ & 10 & 3 \\
\hline 5 & & NS & NS & NS & $0,65 \mathrm{NS}$ & 10 & 3 \\
\hline 6 & & NS & NS & NS & $4,20 \mathrm{NS}$ & 10 & 3 \\
\hline 7 & & $* * *$ & $* * *$ & $*$ & $18.50 * * *$ & 12 & 3 \\
\hline 8 & & $* * *$ & NS & $* *$ & $27,12 * * *$ & 16 & 3 \\
\hline
\end{tabular}

F - Fígado; VP - veia porta; VM - vasos mesentéricos.

NS - não significativo

*** significativo a nível de $0,1 \%$

* significativo a nível de $1 \%$

* significativo a nível de $5 \%$

$\mathrm{n}=$ número de camundongos sacrificados

$\mathrm{k}==$ número de localização dos vormes

$r=$ indice do teste de Friedman

Nas infecçōes por machos, o deslocamento entre o fígado, veia porta e vasos mesentéricos é menos intenso, enquanto nas infecções por esquistossomos fêmeos, além do deslocamento ser mais acentuado, evidenciamos um comportamento nitidamente ciclico.

Pode-se verificar pelas Tabelas $1,4,7$, 8 e 9 que o coeficiente de variação apresentado pelos dados referentes a média numérica dos vermes colhidos no fígado, veia porta e vasos mesentéricos pode ser considerado alto, porém na maior parte dos casos é nítida a tendência de sua diminuição com o passar do tempo de infecção.

Standen 10 (1953) não verificou a presença de fêmeas nos vasos mesentéricos de camundongos com infecção unissexual. Este fato pode ser explicado pelo pequeno tamanho das fêmeas nas infecções unissexuais, passando despercebidas durante a perfusão.

Nas infecções bissexuais (Figs. 3, 4 e 5), verificamos que machos e fêmeas apresentam padrão de deslocamento semelhante.

Como foi observado por Standen ${ }^{10}$ (1953), através de gráfico elaborado por Brener : (1959), machos e fêmeas deslocam-se para os vasos mesentéricos a partir da sexta semana, coincidindo com o aparecimento dos primeiros ovos no intestino.

Verificamos, ainda, em camundongos com infecção bissexual, e sacrificados na oitava semana pós-infecção, a presença de vermes nos pulmões. Barbosa e col.1 (1978) relatam a ocorrência de esquistossômulos nos pulmōes nesse mesmo período de infecção. Nossa observação, entretanto, refere-se a presença de vermes adultos nos brônquios, ou de localização subpleural.

Imbert-Establet ${ }^{3}$ (1980) e Jourdane e Imbert-Establet 5 (1980), verificaram a migração de esquistossomos adultos para os vasos pulmonares através do coração direito. Jourdane 4 (1978) assinalou que esta migração ocorre secundariamente a migração dos esquistossômulos dos pulmões para o fígado. Estas observações de Jourdane e de Imbert-Establet foram feitas em Rattus rattus parasitados por S. mansoni.

$O$ comportamento migratório dos esquistossomos nas infecções uni e bissexuais evidencia a influência do sexo no deslocamento dos vermes no plexo porta.

A influência do sexo no comportamento migratório dos vermes no plexo porta, 
ZANOTTI, E.M. et al. Localizaçăo de Schistosoma mansoni no plexo porta de Mus musculus experimentalmente infectados por um só sexo do trematódeo. Rev. Saúde públ., S. Paulo, 16: $220-32,1982$.

estudada através das infecções uni e bissexuais, mostra que o seu deslocamento visa o acasalamento que ocorre, principalmente, no interior dos vasos mesentéricos. Este fenômeno coincidiu com o inicio da oviposição.

Nás infecções unissexuais, o deslocamento dos esquistossomos se processa principalmente entre os vasos portais intra-hepáticos e a veia porta, sendo raro o encontro de vermes nos vasos mesentéricos. Observamos que este deslocamento é cíclico, sendo que as deflexões apresentam maior freqüência nas infecções por fêmeas.

No decorrer do experimento, nos camundongos com infecção bissexual não observamos migração dos esquistossomos com caráter cíclico. Os vermes migraram dos vasos intra-hepáticos para os vasos mesentéricos, utilizando a veia porta apenas como "ponte de passagem". Como observamos o mesmo comportamento entre machos e fêmeas, deduz-se que esta migração foi feita com os vermes acasalados.

ZANOTTl, E. M. et al. [Localization of Schistosoma mansoni in the portal system of Mus musculus infucted experimentally by a single sex of the trematode]. Rev. Saúde públ., S. Paulo, 16:220-32, 1982.

ABSTRACT: S. mansoni migration in mice infected by unisexual or bisexual modes was studied. The research shows the influence of the adult worms. It seems that in the bisexual infections the schistosome migration to the mesenteric vessels takes place with a view to copulation and oviposition.

UNITERMS: Schistosoma mansoni, migration. Schistosomiasis. Mus musculus.

\section{REFERENCIAS BIBLIOGRAFICAS}

1. BARBOSA, A.M.; PELLEGRINO, J.; COELHO, P.M.Z. \& SAMPAIO. I.B.M. Quantitative aspects of the migration and evolutive asynchronism of Schistosoma mansoni in mice. Rev. Inst. Med. trop. S. Paulo, 20:121-32, 1978.

2. BRENER, Z. Esquistossomose experimental Rev. bras. Malar, 11:473-506, 1959.

3. IMBERT-ESTABLET, D. Voie de migration des adultes de Schistosoma mansoni chez Rattus rattus du système veineux mesentérique aux poumons. C.R. Acad. Soi Paris, 290:531.4 1980 .

4. JOURDANE, J. Pernissivité du rat (Rattus rattus) de Guadeloupe à l'egard de Schistosoma mansoni et mise en évidence $d^{\prime}$ une migration des chistosomes adultes vers les poumons. C.R. Acad. Sci. Paris, 286:1001,4 1978.
5. JOURDANE, J. \& IMBERT-ESTABLET, D. Etude expérimentale de la permissivité du rat sauvage (Rattus rattus) de Guadeloupe à l'egard de Schistosoma mansoni. Hypothèse sur le rôle de cet hote dans la dynamique des foyers naturels. Acta trop., 37:41-51, 1980.

6. MAGALHÁS, L.A. Técnica para a avaliação da viabilidede de penetração de cercárias de Schistosoma mansoni em Mus musculus. Hospital, Rio de Janeiro, $75: 137-40,1969$

7. PARAENSE, W.L. \& SANTOS, J.M. O sexo do Schistosoma mansoni nas infecções produzidas por cercárias de um único molusco. Mem. Inst. Oswaldo Cruz, 47:35-49, 1949.

8. PARAENSE, W.L. Observações adicionaıs sobre o sexo do Schistosoma mansoni nas infecçóes por cercárias de um único molusco. Mem. Inst. Oswaldo Cruz, $47: 535-43,1949$. 
ZANOTTI, E.M. et al. Localização de Schistosoma mansoni no plexo porta de Mus musculus experimentalmente infectados por um só sexo do trematódeo. Rev. Saúde públ., S. Paulo, 16: 220-32, 1982.

9. SAMBON, L.W. Descriptions of some new species of animal parasites. Proc. Zool. Soc. London, p. 282-3, 1907. [separata]

10. STANDEN, O.D. The relationships of sex in Schistosoma mansoni to migration within the hepatic portal system of experimentally infected mice. Ann. trop. Med. Parasit,, 47:139-45, 1953.
11. YOLES, T.K.; MOORE, P.V.; DEGINSTI, D.L.; RIPSON, C.A. \& MELENEY, H.E. A technique for the perfusion of laboratory animals for the recovery of schis. tosomes. J. Parasit., 33:419-26, 1947.

Recebido para publicasão em 29/12/1981 Aprovado para publicąão em 14/04/1982

\section{RESUMO/BOOK REVIEW}

SHELLEY, Louise I. Crime and modernization: the impact of industrialization and urbanization on crime. Carbondale, Ill., Southern Illionois University Press, 1981. $186 \mathrm{p}$.

Em seis capitulos o autor considera as maneiras pelas quais o processo de modernização tem afetado os coeficientes de criminalidade no decurso das etapas iniciais e posteriores do desenvolvimento social. Objetiva com isso verificar se a transição entre os estados de sociedade subdesenvolvida e desenvolvida altera o quadro do comportamento e se, da modernização daí decorrente resulta mudança significante nas características da população criminosa. Dividido em três partes, o livro analisa aspectos fundamentais. A primeira é dedicada à perspectiva teórica do crime e sua focalização no desenvolvimento industrial. Nas outras duas, considera os aspectos encontrados nas nações capitalistas e socialistas, dividindo os relativos àquelas, em países desenvolvidos e em desenvolvimento. Conclui considerando o binômio modernização e crime, nesse contexto global e histórico. O livro abre perspectivas para o estudo desse problema social e se constitui em valioso repertório de informação. Acompanha-o bibliografia selecionada.

Oswaldo Paulo Forattini 